Subscriber access provided by Caltech Library

\title{
Letter
}

\section{Enhanced Stability and Efficiency for Photoelectrochemical lodide Oxidation by Methyl Termination and Electrochemical Pt Deposition of n-Si Microwire Arrays}

Shane Ardo, Elizabeth A. Santori, Hal S. Emmer, Ronald Grimm, Matthew J. Bierman, Bruce S. Brunschwig, Harry A Atwater, and Nathan S. Lewis

ACS Energy Lett., Just Accepted Manuscript • DOI: 10.1021/acsenergylett.9b01529 • Publication Date (Web): 25 Jul 2019

Downloaded from pubs.acs.org on July 26, 2019

\section{Just Accepted}

"Just Accepted" manuscripts have been peer-reviewed and accepted for publication. They are posted online prior to technical editing, formatting for publication and author proofing. The American Chemical Society provides "Just Accepted" as a service to the research community to expedite the dissemination of scientific material as soon as possible after acceptance. "Just Accepted" manuscripts appear in full in PDF format accompanied by an HTML abstract. "Just Accepted" manuscripts have been fully peer reviewed, but should not be considered the official version of record. They are citable by the Digital Object Identifier (DOI®). "Just Accepted" is an optional service offered to authors. Therefore, the "Just Accepted" Web site may not include all articles that will be published in the journal. After a manuscript is technically edited and formatted, it will be removed from the "Just Accepted" Web site and published as an ASAP article. Note that technical editing may introduce minor changes to the manuscript text and/or graphics which could affect content, and all legal disclaimers and ethical guidelines that apply to the journal pertain. ACS cannot be held responsible for errors or consequences arising from the use of information contained in these "Just Accepted" manuscripts. 


\title{
Enhanced Stability and Efficiency for Photoelectrochemical Iodide Oxidation by Methyl Termination and Electrochemical Pt Deposition of n-Si Microwire Arrays
}

\author{
Shane Ardo, ${ }^{a}$ Elizabeth A. Santori, ${ }^{a}$ Hal S. Emmer, ${ }^{b}$ Ronald L. Grimm, ${ }^{\text {a }}$ Matthew J. \\ Bierman, ${ }^{\text {a }}$ Bruce S. Brunschwig, ${ }^{\text {c }}$ Harry A. Atwater, ${ }^{\text {bd }}$ and Nathan S. Lewis ${ }^{\text {acd* }}$ \\ aDivision of Chemistry and Chemical Engineering, California Institute of Technology, \\ 1200 E. California Blvd., Pasadena, California 91125, USA \\ bThomas J. Watson Laboratories of Applied Physics, California Institute of Technology, \\ 1200 E. California Blvd., Pasadena, California 91125, USA \\ 'Beckman Institute, California Institute of Technology, 1200 E. California Blvd., \\ Pasadena, California 91125, USA. \\ E-mail: nslewis@caltech.edu; Fax: +1 626 395-8867; Tel: +1 626 395-6335 \\ ${ }^{\mathrm{d} K a v l i}$ Nanoscience Institute, California Institute of Technology, 1200 E. California \\ Blvd., Pasadena, California 91125, USA \\ *corresponding author
}

\begin{abstract}
Arrays of Si microwires doped n-type and terminated by methyl groups have been used, with or without deposition of a Pt electrocatalyst, to photoelectrochemically oxidize $\mathrm{I}^{-}$ (aq) to $\mathrm{I}_{3}{ }^{-}(\mathrm{aq})$ in $7.6 \mathrm{M} \mathrm{HI}(\mathrm{aq})$. Under conditions of iodide oxidation, methyl-terminated n-Si microwire arrays exhibited stable short-circuit photocurrents over a timescale of days, albeit with low energy-conversion efficiencies. In contrast, electrochemical deposition of $\mathrm{Pt}$ onto methyl-terminated $\mathrm{n}$-Si microwire arrays consistently yielded energy-conversion efficiencies of $\sim 2 \%$ for iodide oxidation, with an open-circuit photovoltage of $\sim 400 \mathrm{mV}$ and a short-circuit photocurrent density of $\sim 10 \mathrm{~mA} \mathrm{~cm}^{-2}$ under $100 \mathrm{~mW} \mathrm{~cm}^{-2}$ of simulated Air Mass 1.5G illumination. Platinized electrodes were stable for $>200 \mathrm{~h}$ of continuous operation, with no discernable loss of Si or Pt. Pt deposited using electron-beam evaporation also resulted in stable photoanodic operation of the methyl-terminated n-Si microwire arrays, but yielded substantially lower photovoltages than when Pt was deposited electrochemically.
\end{abstract}




\section{TOC GRAPHIC}



Global climate change caused by anthropogenic greenhouse gases is a serious concern. Solar energy utilization is particularly interesting because solar panels are easily deployable on various size scales and in many regions of the world electricity from solar panels is cost-competitive with electricity derived from greenhouse gases. ${ }^{1,2}$ However, at certain times of the day in some parts of the world solar panels provide more electricity than demanded by the country. This situation can occur at a level of solar panel installation that provides as little as $\sim 20 \%$ of the daily electricity demand of the country, ${ }^{3,4}$ therefore necessitating substantial installment of energy storage technologies to enable $100 \%$ renewable electricity generation to be effectively utilized. Silicon represents over $90 \%$ of the installed solar panel capacity ${ }^{1}$ and hence identification of uses for silicon for direct light-to-chemical energy storage is of current technological interest. Arrays of Si microwires $(\mathrm{MWs})^{5-14}$ and nanowires ${ }^{15-23}$ are interesting platforms for the fabrication of artificial photosynthetic devices. The high aspect ratio of the wires allows for effective light absorption along the length of the wire, while enabling short, radial charge-carrier collection distances to electrocatalysts optimally integrated in a high surface-area structure. ${ }^{24}$ The porosity of the wire array allows for facile reactant access 
and product egress to/from the internal area of the morphologically structured light absorber, and provides a minimal path length for ionic conduction to and through a supporting membrane. ${ }^{25}$

Renewable energy storage in $\mathrm{H}_{2}$ from water or direct $\mathrm{CO}_{2}$ reduction from the atmosphere represent particularly interesting chemical storage options because they form simple high-energy-dense chemicals and/or are carbon neutral processes. However, both of these reactions still present major challenges, ${ }^{26}$ in particular because both reactions utilize electrons and protons from water via its oxidation to $\mathrm{O}_{2}$ by a complex fourelectron, four-proton process to store $>1.0 \mathrm{~V}$ of potential. This kinetically challenging process only has an $\sim 40 \%$ roundtrip efficiency for $\mathrm{H}_{2}$ energy storage via water electrolysis and use in a polymer-electrolyte-membrane fuel cell. ${ }^{27,28}$ Moreover, the band gap of $\mathrm{Si}$ is $1.12 \mathrm{eV}$, and even state-of-the-art Si typically exhibits photovoltages at the maximum power point of only $\sim 0.6 \mathrm{~V}$ under 1 Sun of illumination. ${ }^{29}$ Hence, Si by itself, either as an individual light absorber or in a tandem structure in which two Si light absorbers are arranged optically and electrically in series, cannot provide the photovoltage necessary to drive water electrolysis or sustainable $\mathrm{CO}_{2}$ reduction. ${ }^{30} \mathrm{Si}$ is also unstable toward anodic oxidation in aqueous electrolytes, and thus benefits from kinetic stabilization strategies such as use of one-electron-transfer redox species in nonaqueous solvents or protective coatings. ${ }^{31-34}$

Identification of simple alternative electron sources to water are timely research endeavors. Halides in particular allow for $\sim 90 \%$ roundtrip efficiency for $\mathrm{H}_{2}$ energy storage and use. ${ }^{28,35}$ Therefore, photoelectrolysis of $\mathrm{HI}(\mathrm{aq})$ to produce $\mathrm{H}_{2}(\mathrm{~g})$ and $\mathrm{I}_{3}{ }^{-}(\mathrm{aq})$ is one potential approach for solar energy storage using a Si light-absorber. The 
minimum voltage needed for the electrolysis reaction is only $\sim 0.55 \mathrm{~V}$ under standardstate conditions ${ }^{36}$ and is $\sim 0.25 \mathrm{~V}$ in highly concentrated $\mathrm{HI}(\mathrm{aq}),{ }^{37}$ both of which can be provided in principle by single, non-tandem Si MW arrays. ${ }^{38-40}$ A demonstration of the utility of Si MW arrays for the unassisted electrolysis of HI(aq) would also provide a step along a pathway toward solar fuel production. Such a system, however, requires a method to suppress the anodic oxidation and passivation of $\mathrm{Si}$ in aqueous solutions. Unassisted photoelectrolysis of $\mathrm{HI}(\mathrm{aq})$ has been demonstrated using membraneembedded p-type Si MW arrays in which the Si MWs served as the photocathode and iodide was oxidized at a back metal contact to the MWs. ${ }^{41}$ Moreover, planar singlecrystalline $\mathrm{n}-\mathrm{Si}(111)$ photoanodes have been shown to be stable when in contact with $\mathrm{Fe}(\mathrm{CN})_{6}{ }^{3-/ 4-}(\mathrm{aq})$ solutions for hours of continuous illumination, if the Si surface is terminated with methyl groups using a two-step chlorination/alkylation surface functionalization process. ${ }^{42}$ Methyl termination also introduces a surface dipole that shifts the band edges in contact with a variety of redox couples, producing increases in photovoltage for such functionalized photoanodes relative to the behavior of $\mathrm{H}$ terminated $\mathrm{n}$-Si(111) photoelectrodes. $^{43}$ We demonstrate herein the use of methylterminated Si MWs, in conjunction with surface-bound Pt electrocatalysts for $\mathrm{I}^{-}$oxidation, to enhance the stability of n-Si MW array electrodes under photoanodic operation while effecting the solar-driven oxidation of $\mathrm{I}^{-}(\mathrm{aq})$ to $\mathrm{I}_{3}^{-}(\mathrm{aq})$ in $7.6 \mathrm{M} \mathrm{HI}(\mathrm{aq})$ at an ideal regenerative-cell energy-conversion efficiency, ${ }^{41} \eta_{\text {IRC }}$, of $>1 \%$ for $>200$ h of continuous operation under simulated 1 Sun illumination (Figure 1). 




Figure 1. Si microwire array photoanode that is the focus of this work and effects the stable light-driven oxidation of $\mathrm{I}^{-}(\mathrm{aq})$ to $\mathrm{I}_{3}{ }^{-}(\mathrm{aq})$ in $7.6 \mathrm{M} \mathrm{HI}(\mathrm{aq})$. The microwires are doped n-type, are surface-terminated with methyl groups, contain surface-bound $\mathrm{Pt}$ electrocatalysts, and contain an oxide boot to attenuate electrochemical shunts.

Crystalline Si MW arrays were grown by the vapor-liquid-solid growth method on patterned (111)-oriented Si substrates. ${ }^{41,44,45}$ The desired microwire diameter and spacing was produced by lithographically patterning $3 \mu \mathrm{m}$ diameter circular holes, with a center-to-center pitch of $7 \mu \mathrm{m}$, into an oxide overlayer formed on a degenerately doped, non-photoactive $\operatorname{Si}(111)$ substrate. ${ }^{45}$ The holes in the oxide layer were subsequently filled with thermally evaporated $\mathrm{Cu}$, which served as the $\mathrm{Si}$ growth catalyst. The doping type and dopant density of the n-Si MWs was controlled by use of $\mathrm{PH}_{3}$ during growth, and the height of the microwires was controlled by the growth time as well as by the position of the substrate in the reactor. After growth and cleaning, the n-Si MW arrays were functionalized with methyl groups by a two-step chlorination/alkylation reaction sequence. ${ }^{43,46-48}$ As needed, Pt was then deposited using electron-beam evaporation or by electrochemical deposition from $5 \mathrm{mM} \mathrm{K}_{2} \mathrm{PtCl}_{4}$ (aq) by passing $>100 \mathrm{mC} \mathrm{cm}^{-2}$ of cathodic charge density at $-1.0 \mathrm{~V}$ versus a saturated calomel electrode (SCE), with additional details available in the Supporting Information. 
Four-point probe measurements on single Si MWs yielded calculated resistivities, and therefore calculated dopant densities, ${ }^{15}$ that were not related linearly to the partial pressure of the $\mathrm{PH}_{3}$ dopant gas used during wire growth (Figure S1). A series of measurements on the n-Si MWs that were etched by $\mathrm{KOH}(\mathrm{aq})$ suggested that the microwire shells were substantially more conductive than the cores. The radial dependence of the dopant density is consistent with deposition of excess P by a vaporsolid-solid growth mechanism. ${ }^{49,50}$ A high-temperature thermal oxide "booting" procedure was then applied to: (i) further distribute the dopants homogeneously throughout the radius of the microwire; and (ii) etch some of the excess high concentration dopants from the wire shell prior to thermal annealing. This booting process was required to obtain high-quality MW arrays that exhibited current density versus potential $(J-E)$ behavior (Figure S2) consistent with that previously reported in non-aqueous electrolytes containing a one-electron-transfer, outer-sphere ferrocene-based redox couple. ${ }^{45}$ The normal incidence spectral response under these conditions (Figure S3) exhibited behavior that was similar to that reported previously for p-type or intrinsic (i.e. unintentionally doped) $\mathrm{Si} \mathrm{MW}$ arrays, ${ }^{51,52}$ but was n-type in character for these deliberately doped n-Si MW arrays. Changing the orientation of the Si MW arrays withrespect-to the direction of propagation of incoming light has been shown to result in increased external quantum yields, even beyond the limit imposed by ergodic ray-optic light trapping. ${ }^{51}$ In addition, improved light management techniques using for example arrays of microcones can yield high absorption over a large range of angles of the incident illumination. ${ }^{53}$ Consistently, in the dark the MW arrays exhibited current 
rectification, evidenced by passing substantial cathodic currents at negative potentials in conjunction with small anodic currents at positive potentials (Figure S2 and S4).

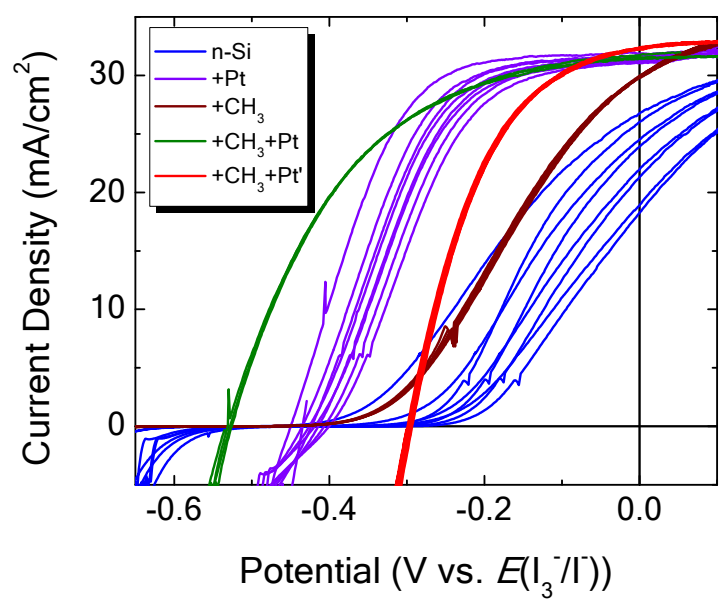

Figure 2. Three-electrode current density versus potential data recorded under $100 \mathrm{~mW}$ $\mathrm{cm}^{-2}$ of simulated AM1.5 G solar illumination for planar, single-crystalline, n-type $\mathrm{Si}(111)$ electrodes immersed in Ar-purged $~ 7.6 \mathrm{M} \mathrm{HI}$ (aq) containing adventitious $\mathrm{I}_{3}{ }^{-}$with or without (blue) various combinations of surface terminations and catalyst treatments: methylation $\left(+\mathrm{CH}_{3}\right)$, electrochemical Pt deposition $(+\mathrm{Pt})$, electron-beam evaporation of $\mathrm{Pt}$ $\left(+\mathrm{Pt}^{\prime}\right)$.

Figure 2 displays representative photoelectrochemical $J-E$ data of planar, singlecrystalline $\mathrm{n}-\mathrm{Si}(111)$ electrodes in contact with Ar-purged $~ 7.6 \mathrm{M} \mathrm{HI}(\mathrm{aq})$ that by visual inspection contained adventitious $\mathrm{I}_{3}^{-}(\mathrm{aq})$. The surfaces were: $\mathrm{H}-\mathrm{Si}(111)$ (blue); $\mathrm{Pt}$ deposited electrochemically on $\mathrm{H}-\mathrm{Si}(111)$ (purple); $\mathrm{CH}_{3}$-terminated $\mathrm{Si}(111)$ (brown); $\mathrm{Pt}$ deposited electrochemically on $\mathrm{CH}_{3}$-terminated $\mathrm{Si}(111)$ (green); or Pt deposited using electron-beam evaporation on $\mathrm{CH}_{3}$-terminated $\mathrm{Si}(111)$ (red). Even in highly concentrated $\sim 7.6 \mathrm{M} \mathrm{I}^{-}(\mathrm{aq})$, the $\mathrm{H}$-terminated $\mathrm{n}-\mathrm{Si}(111)$ electrodes exhibited a large resistance near open-circuit conditions, low fill factors, and a rapid degradation of performance under illumination. This loss in performance is attributed to oxidation and passivation of the $\mathrm{Si}$ surface under photoanodic operation. Deposition of Pt without prior methylation 
provided enhanced rates of $\mathrm{I}^{-}$oxidation, yet resulted in similarly low stability to that observed for $\mathrm{H}$-terminated $\mathrm{Si}(111) . \mathrm{CH}_{3}$-termination alone resulted in an electrode that was stable on the timescale of days, but exhibited a very low fill factor, attributable to the slow interfacial charge-transfer rate constant for the oxidation of $\mathrm{I}^{-}$at $\mathrm{Si}$ surfaces. ${ }^{54,55}$ Open-circuit voltages, $V_{\text {oc }}$, for $\mathrm{CH}_{3}$-terminated n-Si(111) photoelectrodes were consistently larger than those observed for H-terminated n-Si(111) photoelectrodes, regardless of whether electrochemically deposited Pt was present. This behavior is consistent with expectations in which an interfacial surface dipole arising from $\mathrm{Si}-\mathrm{CH}_{3}$ bonds produces a negative shift in the band-edge positions of $\mathrm{CH}_{3}-\mathrm{Si}(111)$ surfaces relative to $\mathrm{H}-\mathrm{Si}(111)$ surfaces. ${ }^{43,56,57}$ In contrast to the other electrodes, $\mathrm{CH}_{3}$-termination in combination with electrochemical deposition of Pt produced high fill factors and resulted in planar $\mathrm{n}$-Si photoanodes that exhibited reproducible, stable, and efficient photooxidation of $\mathrm{HI}(\mathrm{aq}){ }^{37}$ Hence, through judicious choice of the Pt deposition protocol, large photovoltages can be obtained even though Pt typically forms interfacial silicides that limit the photovoltage to $<500 \mathrm{mV}$ under 1 Sun illumination, ${ }^{58}$ which is similar to the behavior we observed for Pt deposited by electron-beam evaporation.

Figure 3 displays the representative photoelectrochemical $J-E$ performance of a methylated n-Si MW array electrode in contact with 7.6 M HI(aq), before and after electrochemical deposition of Pt. Methylated n-Si MW arrays were not easily wetted by water or aqueous electrolytes, although repeated immersion of electrodes into either of these solutions $(\sim 10$ times) ultimately resulted in contact to the microwire arrays so that they were suitable for measurements. Methylated n-Si MW arrays that contained electrochemically deposited Pt consistently exhibited $V_{\text {oc }} \sim 400 \mathrm{mV}$, short-circuit current 
densities, $J_{\mathrm{sc}}$, of $\sim 10 \mathrm{~mA} \mathrm{~cm}{ }^{-2}$ at the Nernstian potential for oxidation of $\mathrm{I}^{-}$to $\mathrm{I}_{3}^{-}, E\left(\mathrm{I}_{3}^{-} / \mathrm{I}^{-}\right)$, and an ideal regenerative-cell energy-conversion efficiency, $\eta_{\text {IRC }}$, of $\sim 2.0 \%$ under 1 Sun of simulated solar illumination. Figure S4 shows the behavior of the best-performing sample measured during the course of this work.



Figure 3. Three-electrode current density versus potential data recorded in the dark (dashed) or under $100 \mathrm{~mW} \mathrm{~cm}{ }^{-2}$ of simulated AM1.5 G solar illumination (solid lines) for a methylated n-type Si MW array electrode immersed in Ar-purged 7.6 M HI(aq) electrolyte containing adventitious $\mathrm{I}_{3}^{-}$before (brown) or after (green) electrochemical deposition of Pt.

Prior studies reported that methyl-termination of planar, single-crystalline nSi(111) surfaces followed by Pt deposition resulted in efficient and stable photocurrent for the photooxidation of aqueous iodide or bromide. ${ }^{17,37,59}$ Photocurrents for $\mathrm{I}^{-}$oxidation using H-terminated $\mathrm{n}$-Si nanowires with surface-deposited $\mathrm{Pt}$, but in the absence of surface methylation, were shown to exhibit modest stability on the timescale of days. ${ }^{37}$ However, the platinized n-Si MW arrays investigated herein that did not contain $-\mathrm{CH}_{3}$ groups consistently exhibited poor stability for $\mathrm{I}^{-}(\mathrm{aq})$ oxidation. In contrast, the n-Si MW arrays that had been platinized after $\mathrm{CH}_{3}$-termination showed stable photocurrents for $>$ 
$200 \mathrm{~h}$ of near-continuous $\mathrm{I}^{-}(\mathrm{aq})$ photo-oxidation, with $J_{\text {sc }}$ decreasing by $<15 \%$ after $200 \mathrm{~h}$ of continuous cyclic voltammetric sweeping (Figure 4). This small decrease in $J_{\text {sc }}$ over time is consistent with our observation of light attenuation by photogenerated $\mathrm{I}_{3}{ }^{-}$ measured using a calibrated silicon photodiode. However, the small change in the shape of the $J-E$ behavior to one that is consistent with increased shunting suggests that at a minimum oxidation of the surface of the microwire surfaces was likely, which is not surprising given expected imperfect methylation of the non-Si(111) facets on the sidewalls of the microwires due to varied bonding environments and sterics. ${ }^{60} \mathrm{~A} \mathrm{CH}_{3}-$ terminated n-Si MW array that did not contain Pt exhibited stable, but modest, efficiency under the same conditions (Figure S5). This observation is consistent with expectations of stable but attenuated performance for $\mathrm{CH}_{3}$-terminated planar, single-crystalline $\mathrm{n}$ $\mathrm{Si}(111)$ electrodes in the absence of Pt catalysts (Figure 2).

(a)

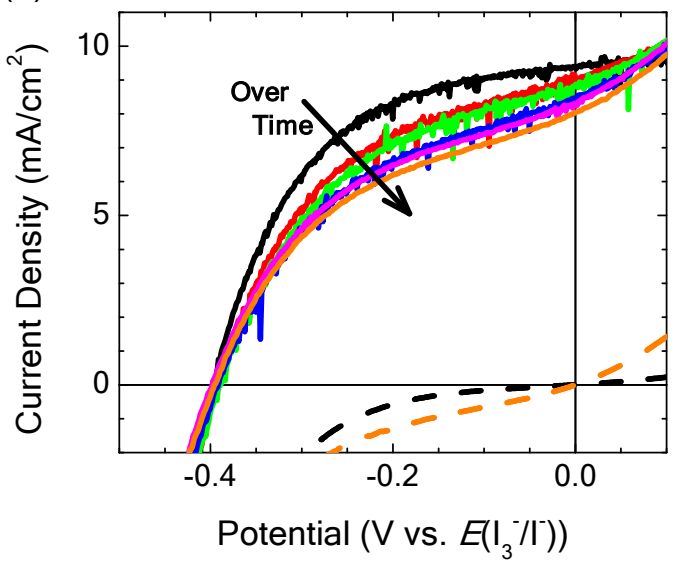

(b)

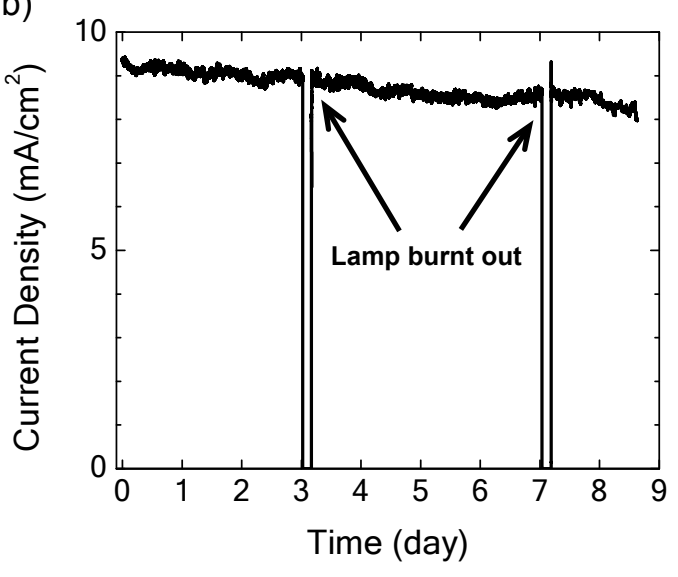

Figure 4. (a) Three-electrode current density versus potential data recorded in the dark (dashed; black initially and orange after $200 \mathrm{~h}$ ) or under $100 \mathrm{~mW} \mathrm{~cm}{ }^{-2}$ of simulated AM1.5 G solar illumination every $50 \mathrm{~h}$, and at $200 \mathrm{~h}$ of near-continuous illumination, for the methylated n-type Si MW array electrode with electrochemically deposited Pt of Figure 3 immersed in Ar-purged $~ 7.6 \mathrm{M} \mathrm{HI}(\mathrm{aq})$ containing adventitious $\mathrm{I}_{3}^{-}$. (b) Threeelectrode chronoamperometry data recorded at a potentiostatic bias of $0 \mathrm{~V}$ versus the Nernstian potential of the solution over $200 \mathrm{~h}$ of $100 \mathrm{~mW} \mathrm{~cm}{ }^{-2}$ of simulated AM1.5 G solar illumination, which totalled $207.5 \mathrm{~h}$ to compensate for the instances when the ELH- 
type W-halogen lamp burnt out and was replaced with a new source.

To assess the feasibility of performing the overall photoelectrolysis of aqueous hydriodic acid, in which the concentration of $\mathrm{I}_{3}^{-}$will increase substantially over time, as well as to assess the quantum yield of $\mathrm{I}_{3}{ }^{-}$formation, $J-E$ data under potentiostatic control were obtained over $21 \mathrm{~h}$ for a platinized, $\mathrm{CH}_{3}$-terminated $\mathrm{n}$-Si MW array sample in $7.6 \mathrm{M}$ $\mathrm{HI}(\mathrm{aq})$ that initially contained adventitious $\mathrm{I}_{3}^{-}$. These data were obtained in a threeelectrode setup in an H-cell configuration in which the working electrode was separated from the Pt counter electrode by a Nafion membrane (Figure 5a). Ex situ spectroscopic detection indicated near unity Faradaic yield for formation of $\mathrm{I}_{3}^{-}(\mathrm{aq})$ (Figure $5 \mathrm{~b}$ ). Consistently, the total anodic charge passed directly correlated with the cathodic limiting current densities ascribable to reduction of $\mathrm{I}_{3}{ }^{-}$at the $\mathrm{Si} \mathrm{MW}$ array photoelectrode. The number of turnovers per Si atom was $\sim 900$ (see Supporting Information for calculation), implying that a $>200$-fold excess in charge was passed relative to the amount of charge required to fully oxidize each $\mathrm{Si}$ atom via a four-hole process. No discernible loss of $\mathrm{Si}$ was observed via scanning-electron microscopy (SEM) before and after the evaluation period of $21 \mathrm{~h}$ (Figure S6), further supporting the conclusion that Si etching and/or loss of Pt was not responsible for the relatively small decrease in photoanodic current density as a function of operating time. A calibrated Si photodiode that was placed in the cell after the electrolysis exhibited $\sim 85 \%$ of its initial response before the electrolysis, consistent with the observed decrease in photocurrent from the Si MW photoanode and indicating that the decay can be consistently ascribed to parasitic light absorption due to the formation of $\mathrm{I}_{3}^{-}$in the cell during the electrolysis. Moreover, the photoactivity was exclusively due to the microwires and not the substrate, because physical removal of the 
microwires yielded planar n-Si electrodes that exhibited essentially no anodic photocurrent under the same conditions, as expected for a degenerately doped n-Si(111) substrate acting as the electrode.

(a)

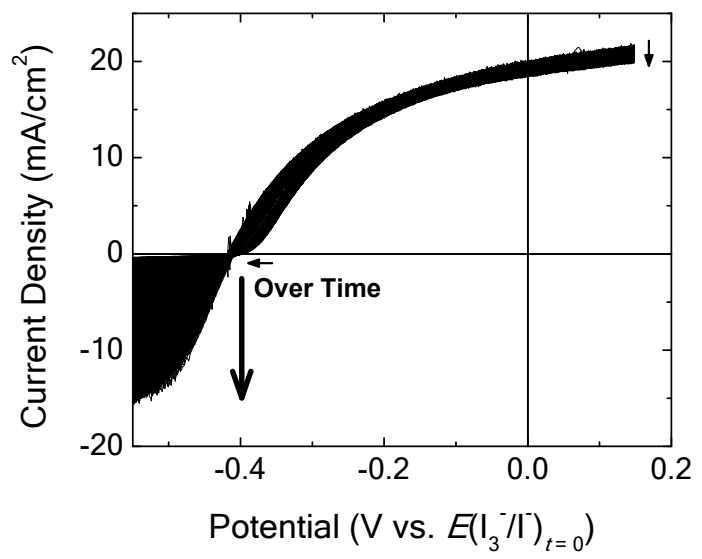

(b)

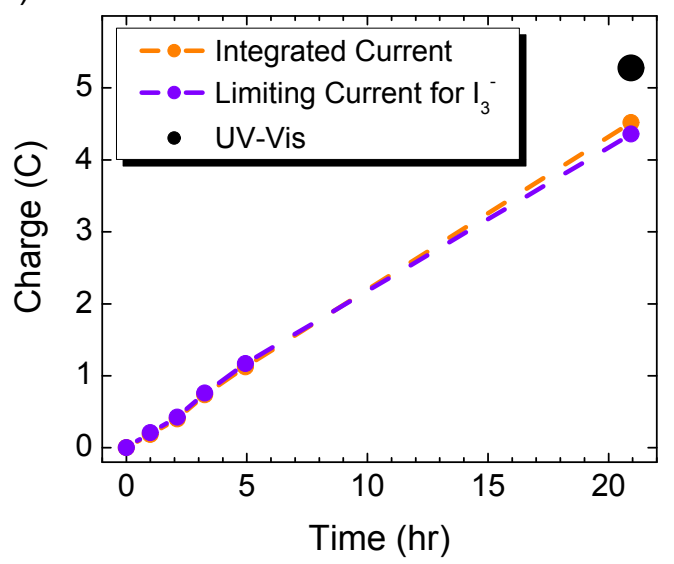

Figure 5. (a) Three-electrode current density versus potential data in an H-cell configuration with the working and counter electrodes separated by a Nafion membrane recorded continuously at a scan rate of $10 \mathrm{mV} \mathrm{s}^{-1}$ under $100 \mathrm{~mW} \mathrm{~cm}{ }^{-2}$ of simulated AM1.5 G solar illumination for an $\mathrm{n}-\mathrm{Si}-\mathrm{CH}_{3} / \mathrm{Pt} \mathrm{MW}$ array electrode immersed in Arpurged $\sim 7.6 \mathrm{M} \mathrm{HI}(\mathrm{aq})$ that initially contained adventitious $\mathrm{I}_{3}{ }^{-}$over $\sim 21 \mathrm{~h}$ of continuous operation. (b) Integrated current data from panel a reported for several times during the measurement (orange) and the scaled limiting cathodic current near $-0.55 \mathrm{~V}$, which is proportional to the amount of $\mathrm{I}_{3}{ }^{-}$in solution. For reference, also shown is the end point concentration of $\mathrm{I}_{3}{ }^{-}$determined using ultraviolet-visible (UV-Vis) electronic absorption spectroscopy in conjunction with the Beer-Lambert law.

Methylation, and in general surface functionalization via solution chemistry, is one of several approaches to protect underlying semiconductors from deleterious surface reactions. ${ }^{61}$ Other protection schemes include physical deposition of materials by, for example, atomic-layer deposition (ALD), sputtering, evaporation, or conversion of the surface by bombardment with atoms or molecules (e.g. nitridation ${ }^{62}$ ), or use of singlelayer coatings including graphene. ${ }^{63}$ Introduction of surface functionality using solution chemistry can provide a conformal coating, for which electron-transfer across the 
interface is either mediated by this layer or requires tunnelling through insulating molecules, ${ }^{64-66}$ such as for the methyl functionality utilized herein. However, even thin conformal layers of metals and metal-oxide materials can absorb and/or reflect a substantial amount of incoming light. ${ }^{67}$ Moreover, coating high-surface-area substrates such as MW arrays and mesoporous thin films is challenging using most physical deposition techniques. Use of both surface chemistry and metal electrocatalysts resulted herein in a large $V_{\text {oc }}$ due to the n- $\mathrm{Si}-\mathrm{CH}_{3}$ surface dipole as well as rapid catalysis from the Pt, resulting simultaneously in a large fill factor for iodide oxidation. Methylation additionally protected the Si surface from extensive oxidation.

The standard electrochemical potential required to oxidize $\mathrm{I}^{-}(a q)$ to $\mathrm{I}_{3}^{-}(a q)$ at unity activity for each species (reaction $1, E^{\mathrm{o}}\left(\mathrm{I}_{3}^{-} / \mathrm{I}^{-}\right)$) is $\sim+0.55 \mathrm{~V}$ versus the normal hydrogen electrode (NHE). ${ }^{36}$ Hence, based on observed values of $V_{\mathrm{oc}}$, the n-Si- $\mathrm{CH}_{3}-\mathrm{Pt}$ MW array electrodes reported herein did not generate sufficient photovoltage under normal-incidence simulated 1 Sun Air Mass (AM) 1.5 G illumination to simultaneously drive half-reaction 1 in conjunction with the reduction of protons to molecular hydrogen, half-reaction 2, each at standard state:

$$
\begin{aligned}
& 3 \mathrm{I}^{-} \rightleftharpoons \mathrm{I}_{3}{ }^{-}+2 \mathrm{e}^{-} \\
& 2 \mathrm{H}^{+}+2 \mathrm{e}^{-} \rightleftharpoons \mathrm{H}_{2}
\end{aligned}
$$

However, the $V_{\mathrm{oc}}$ values do allow for spontaneous, unassisted splitting of $7.6 \mathrm{M} \mathrm{HI}(\mathrm{aq})$, whose non-standard-state concentration results in $E\left(\mathrm{I}_{3}{ }^{-} / \mathrm{I}^{-}\right) \sim+0.25 \mathrm{~V} .{ }^{37}$

The combination of enhanced stability, catalysis, and large $V_{\text {oc }}$ values is a key step toward use of MW arrays for integrated reversible storage of intermittent photon energy as $\mathrm{H}_{2}$ using a variety of electron sources, such as other hydrohalic acids (e.g. $\mathrm{HBr}(\mathrm{aq})$ ) or $\mathrm{H}_{2} \mathrm{O}$. The benefits of using hydrohalic acid fuel precursors are: $(i)$ some are abundant; 
(ii) the thermodynamics required for these reactions can be supplied by a single lightabsorber material used in efficient and commercial photovoltaics, hence the lightabsorber materials have decades of proven research and development successes; and (iii) the electron-transfer chemistry between most materials and halides is extremely rapid meaning little energy is lost during photoelectrochemical oxidation and subsequent reduction in a redox flow battery. These facts have led photoelectrochemical redox flow batteries to be an active area of promising research. ${ }^{68-73}$ Toward this, inexpensive carbon-based materials could be deposited on Si MW arrays as electrodeposited organic polymers or high surface area graphitic materials, therefore enabling small overpotentials for the hydrohalic redox reactions and enabling a better match between the available current from unconcentrated sunlight and the load from the electrochemical reactions, catalysts, and electrolyte. ${ }^{32}$

\section{Acknowledgments}

This work was supported by the National Science Foundation (NSF) Center for Chemical Innovation (CCI) Powering the Planet (grants CHE-0802907, CHE-0947829, and NSF$\mathrm{ACCF}$ ) grants, and made use of the Molecular Materials Resource Center of the Beckman Institute at Caltech and the Kavli Nanoscience Institute at Caltech. S.A. acknowledges support from a U.S. Department of Energy, Office of Energy Efficiency and Renewable Energy (EERE) Postdoctoral Research Award under the EERE Fuel Cell Technologies Program. 
Supporting Information Available: additional experimental details, mathematical analysis of Si microwire array stability, single Si microwire dopant density as a function of $\mathrm{PH}_{3}$ flow rate, performance of a $\mathrm{Si}$ microwire array in non-aqueous electrolyte, spectral response of a $\mathrm{Si}$ microwire array in non-aqueous electrolyte, stability of a methylated Si microwire array in aqueous electrolyte, and scanning electron micrograph images of single Si microwires with electrochemically deposited Pt.

\section{References}

(1) Jean, J.; Brown, P. R.; Jaffe, R. L.; Buonassisi, T.; Bulović, V. Pathways for Solar Photovoltaics. Energy \& Environmental Science 2015, 8, 1200-1219.

(2) U.S. Energy Information Administration. Levelized Cost and Levelized Avoided Cost of New Generation Resources in the Annual Energy Outlook; 2019.

(3) National Research Council. The National Academies Summit on America's Energy Future: Summary of a Meeting; 2008.

(4) Hou, Q.; Zhang, N.; Du, E.; Miao, M.; Peng, F.; Kang, C. Probabilistic Duck Curve in High PV Penetration Power System: Concept, Modeling, and Empirical Analysis in China. Applied Energy 2019, 242, 205-215.

(5) Hou, Y.; Abrams, B. L.; Vesborg, P. C. K.; Björketun, M. E.; Herbst, K.; Bech, L.; Setti, A. M.; Damsgaard, C. D.; Pedersen, T.; Hansen, O.; et al. Bioinspired Molecular Co-Catalysts Bonded to a Silicon Photocathode for Solar Hydrogen Evolution. Nature Materials 2011, 10, 434-438.

(6) Warren, E. L.; Atwater, H. A.; Lewis, N. S. Silicon Microwire Arrays for Solar Energy-Conversion Applications. The Journal of Physical Chemistry C 2014, 118 , 747-759.

(7) Lewis, N. S. Developing a Scalable Artificial Photosynthesis Technology through Nanomaterials by Design. Nature Nanotechnology 2016, 11, 1010-1019.

(8) Chen, C.-J.; Yang, K.-C.; Liu, C.-W.; Lu, Y.-R.; Dong, C.-L.; Wei, D.-H.; Hu, S.F.; Liu, R.-S. Silicon Microwire Arrays Decorated with Amorphous HeterometalDoped Molybdenum Sulfide for Water Photoelectrolysis. Nano Energy 2017, 32, 422-432.

(9) Bazri, B.; Lin, Y.-C.; Lu, T.-H.; Chen, C.-J.; Kowsari, E.; Hu, S.-F.; Liu, R.-S. A Heteroelectrode Structure for Solar Water Splitting: Integrated Cobalt Ditelluride across a $\mathrm{TiO}_{2}-$ Passivated Silicon Microwire Array. Catalysis Science \& Technology 2017, 7, 1488-1496.

(10) Vijselaar, W.; Westerik, P.; Veerbeek, J.; Tiggelaar, R. M.; Berenschot, E.; Tas, N. 
R.; Gardeniers, H.; Huskens, J. Spatial Decoupling of Light Absorption and Catalytic Activity of Ni-Mo-Loaded High-Aspect-Ratio Silicon Microwire Photocathodes. Nature Energy 2018, 3, 185-192.

(11) Tung, C.-W.; Chuang, Y.; Chen, H.-C.; Chan, T.-S.; Li, J.-Y.; Chen, H. M. Tunable Electrodeposition of Ni Electrocatalysts onto Si Microwires Array for Photoelectrochemical Water Oxidation. Particle \& Particle Systems Characterization 2018, 35, 1700321.

(12) Vijselaar, W.; Tiggelaar, R. M.; Gardeniers, H.; Huskens, J. Efficient and Stable Silicon Microwire Photocathodes with a Nickel Silicide Interlayer for Operation in Strongly Alkaline Solutions. ACS Energy Letters 2018, 3, 1086-1092.

(13) Milbrat, A.; Vijselaar, W.; Guo, Y.; Mei, B.; Huskens, J.; Mul, G. Integration of Molybdenum-Doped, Hydrogen-Annealed $\mathrm{BiVO}_{4}$ with Silicon Microwires for Photoelectrochemical Applications. ACS Sustainable Chemistry \& Engineering 2019, 7, 5034-5044.

(14) Zhou, Z.; Wu, S.; Li, L.; Li, L.; Li, X. Regulating the Silicon/Hematite Microwire Photoanode by the Conformal $\mathrm{Al}_{2} \mathrm{O}_{3}$ Intermediate Layer for Water Splitting. $A C S$ Applied Materials \& Interfaces 2019, 11, 5978-5988.

(15) Goodey, A. P.; Eichfeld, S. M.; Lew, K.-K.; Redwing, J. M.; Mallouk, T. E. Silicon Nanowire Array Photoelectrochemical Cells. Journal of the American Chemical Society 2007, 129, 12344-12345.

(16) Hwang, Y. J.; Boukai, A.; Yang, P. High Density n-Si/n-TiO 2 Core/Shell Nanowire Arrays with Enhanced Photoactivity. Nano Letters 2009, 9, 410-415.

(17) Peng, K.-Q.; Wang, X.; Wu, X.-L.; Lee, S.-T. Platinum Nanoparticle Decorated Silicon Nanowires for Efficient Solar Energy Conversion. Nano Letters 2009, 9, 3704-3709.

(18) Mayer, M. T.; Du, C.; Wang, D. Hematite/Si Nanowire Dual-Absorber System for Photoelectrochemical Water Splitting at Low Applied Potentials. Journal of the American Chemical Society 2012, 134, 12406-12409.

(19) Oh, I.; Kye, J.; Hwang, S. Enhanced Photoelectrochemical Hydrogen Production from Silicon Nanowire Array Photocathode. Nano Letters 2012, 12, 298-302.

(20) Foley, J. M.; Price, M. J.; Feldblyum, J. I.; Maldonado, S. Analysis of the Operation of Thin Nanowire Photoelectrodes for Solar Energy Conversion. Energy \& Environmental Science 2012, 5, 5203-5220.

(21) Liu, C.; Tang, J.; Chen, H. M.; Liu, B.; Yang, P. A Fully Integrated Nanosystem of Semiconductor Nanowires for Direct Solar Water Splitting. Nano Letters 2013, 13, 2989-2992.

(22) Li, X.; Xiao, Y.; Zhou, K.; Wang, J.; Schweizer, S. L.; Sprafke, A.; Lee, J.-H.; Wehrspohn, R. B. Photoelectrochemical Hydrogen Evolution of Tapered Silicon Nanowires. Physical Chemistry Chemical Physics 2015, 17, 800-804.

(23) Zhang, F.-Q.; Hu, Y.; Meng, X.-M.; Peng, K.-Q. Fabrication and Photoelectrochemical Properties of Silicon/Nickel Oxide Core/Shell Nanowire Arrays. RSC Advances 2015, 5, 88209-88213. 
(24) Kayes, B. M.; Atwater, H. A.; Lewis, N. S. Comparison of the Device Physics Principles of Planar and Radial p-n Junction Nanorod Solar Cells. Journal of Applied Physics 2005, 97, 114302.

(25) Spurgeon, J. M.; Walter, M. G.; Zhou, J.; Kohl, P. A.; Lewis, N. S. Electrical Conductivity, Ionic Conductivity, Optical Absorption, and Gas Separation Properties of Ionically Conductive Polymer Membranes Embedded with Si Microwire Arrays. Energy \& Environmental Science 2011, 4, 1772-1780.

(26) Luna, P. De; Hahn, C.; Higgins, D.; Jaffer, S. A.; Jaramillo, T. F.; Sargent, E. H. What Would It Take for Renewably Powered Electrosynthesis to Displace Petrochemical Processes? Science 2019, 364, eaav3506.

(27) Bents, D. J.; Scullin, V. J.; Chang, B.-J.; Johnson, D. W.; Garcia, C. P. HydrogenOxygen PEM Regenerative Fuel Cell Energy Storage System; NASA Report, 2005, NASA/TM-2005-213381.

(28) Pellow, M. A.; Emmott, C. J. M.; Barnhart, C. J.; Benson, S. M. Hydrogen or Batteries for Grid Storage? A Net Energy Analysis. Energy \& Environmental Science 2015, 8, 1938-1952.

(29) Green, M. A.; Hishikawa, Y.; Dunlop, E. D.; Levi, D. H.; Hohl-Ebinger, J.; HoBaillie, A. W. Y. Solar Cell Efficiency Tables (Version 52). Progress in Photovoltaics: Research and Applications 2018, 26, 427-436.

(30) Haynes, W. M. CRC Handbook of Chemistry and Physics; 92nd ed.; CRC Press: Boca Raton, FL, 2011.

(31) Bolts, J. M.; Bocarsly, A. B.; Palazzotto, M. C.; Walton, E. G.; Lewis, N. S.; Wrighton, M. S. Chemically Derivatized N-Type Silicon Photoelectrodes. Stabilization to Surface Corrosion in Aqueous Electrolyte Solutions and Mediation of Oxidation Reactions by Surface-Attached Electroactive Ferrocene Reagents. Journal of the American Chemical Society 1979, 101, 1378-1385.

(32) Simon, R. A.; Wrighton, M. S. Stabilization of n-Type Silicon Photoanodes against Photoanodic Decomposition with Thin Films of Polyacetylene. Applied Physics Letters 1984, 44, 930-932.

(33) Chen, Y. W.; Prange, J. D.; Dühnen, S.; Park, Y.; Gunji, M.; Chidsey, C. E. D.; McIntyre, P. C. Atomic Layer-Deposited Tunnel Oxide Stabilizes Silicon Photoanodes for Water Oxidation. Nature Materials 2011, 10, 539-544.

(34) Hu, S.; Shaner, M. R.; Beardslee, J. A.; Lichterman, M.; Brunschwig, B. S.; Lewis, N. S. Amorphous $\mathrm{TiO}_{2}$ Coatings Stabilize Si, GaAs, and GaP Photoanodes for Efficient Water Oxidation. Science 2014, 344, 1005-1009.

(35) Braff, W. A.; Bazant, M. Z.; Buie, C. R. Membrane-Less Hydrogen Bromine Flow Battery. Nature Communications 2013, 4, 2346.

(36) Pourbaix, M. Atlas of Electrochemical Equilibria in Aqueous Solutions; Pergamon Press Ltd.: Houston, TX, 1966.

(37) Takabayashi, S. Photoelectrochemical Solar Energy Conversion with Metal NanoDotted and Surface-Alkylated n-Type Silicon (n-Si) Electrodes, Ph.D. Thesis, Osaka University, 2005. 
(38) Boettcher, S. W.; Warren, E. L.; Putnam, M. C.; Santori, E. A.; Turner-Evans, D.; Kelzenberg, M. D.; Walter, M. G.; McKone, J. R.; Brunschwig, B. S.; Atwater, H. A.; et al. Photoelectrochemical Hydrogen Evolution Using Si Microwire Arrays. Journal of the American Chemical Society 2011, 133, 1216-1219.

(39) Warren, E. L.; Boettcher, S. W.; Walter, M. G.; Atwater, H. A.; Lewis, N. S. pHIndependent, $520 \mathrm{mV}$ Open-Circuit Voltages of Si/Methyl Viologen ${ }^{2+/+}$ Contacts Through Use of Radial $\mathrm{n}^{+} \mathrm{p}$-Si Junction Microwire Array Photoelectrodes. The Journal of Physical Chemistry C 2011, 115, 594-598.

(40) Kelzenberg, M. D.; Turner-Evans, D. B.; Putnam, M. C.; Boettcher, S. W.; Briggs, R. M.; Baek, J. Y.; Lewis, N. S.; Atwater, H. A. High-Performance Si Microwire Photovoltaics. Energy \& Environmental Science 2011, 4, 866-871.

(41) Ardo, S.; Park, S. H.; Warren, E. L.; Lewis, N. S. Unassisted Solar-Driven Photoelectrosynthetic HI Splitting Using Membrane-Embedded Si Microwire Arrays. Energy \& Environmental Science 2015, 8, 1484-1492.

(42) Bansal, A.; Lewis, N. S. Stabilization of Si Photoanodes in Aqueous Electrolytes through Surface Alkylation. The Journal of Physical Chemistry B 1998, 102, 4058-4060.

(43) Grimm, R. L.; Bierman, M. J.; O’Leary, L. E.; Strandwitz, N. C.; Brunschwig, B. S.; Lewis, N. S. Comparison of the Photoelectrochemical Behavior of HTerminated and Methyl-Terminated Si(111) Surfaces in Contact with a Series of One-Electron, Outer-Sphere Redox Couples in $\mathrm{CH}_{3} \mathrm{CN}$. The Journal of Physical Chemistry C 2012, 116, 23569-23576.

(44) Maiolo, J. R.; Kayes, B. M.; Filler, M. A.; Putnam, M. C.; Kelzenberg, M. D.; Atwater, H. A.; Lewis, N. S. High Aspect Ratio Silicon Wire Array Photoelectrochemical Cells. Journal of the American Chemical Society 2007, 129, $12346-12347$.

(45) Boettcher, S. W.; Spurgeon, J. M.; Putnam, M. C.; Warren, E. L.; Turner-Evans, D. B.; Kelzenberg, M. D.; Maiolo, J. R.; Atwater, H. A.; Lewis, N. S. EnergyConversion Properties of Vapor-Liquid-Solid-Grown Silicon Wire-Array Photocathodes. Science 2010, 327, 185-187.

(46) Bansal, A.; Li, X.; Lauermann, I.; Lewis, N. S.; Yi, S. I.; Weinberg, W. H. Alkylation of Si Surfaces Using a Two-Step Halogenation/Grignard Route. Journal of the American Chemical Society 1996, 118, 7225-7226.

(47) Yahyaie, I.; Ardo, S.; Oliver, D. R.; Thomson, D. J.; Freund, M. S.; Lewis, N. S. Comparison between the Electrical Junction Properties of H-Terminated and Methyl-Terminated Individual Si Microwire/Polymer Assemblies for Photoelectrochemical Fuel Production. Energy \& Environmental Science 2012, 5, 9789.

(48) Bruce, J. P.; Asgari, S.; Ardo, S.; Lewis, N. S.; Oliver, D. R.; Freund, M. S. Measurement of the Electrical Resistance of n-Type Si Microwire/p-Type Conducting Polymer Junctions for Use in Artificial Photosynthesis. The Journal of Physical Chemistry C 2014, 118, 27742-27748. 
(49) Koren, E.; Rosenwaks, Y.; Allen, J. E.; Hemesath, E. R.; Lauhon, L. J. Nonuniform Doping Distribution along Silicon Nanowires Measured by Kelvin Probe Force Microscopy and Scanning Photocurrent Microscopy. Applied Physics Letters 2009, 95, 092105.

(50) Koren, E.; Berkovitch, N.; Rosenwaks, Y. Measurement of Active Dopant Distribution and Diffusion in Individual Silicon Nanowires. Nano Letters 2010, 10, $1163-1167$.

(51) Kelzenberg, M. D.; Boettcher, S. W.; Petykiewicz, J. A.; Turner-Evans, D. B.; Putnam, M. C.; Warren, E. L.; Spurgeon, J. M.; Briggs, R. M.; Lewis, N. S.; Atwater, H. A. Enhanced Absorption and Carrier Collection in Si Wire Arrays for Photovoltaic Applications. Nature Materials 2010, 9, 239-244.

(52) Santori, E. A.; Maiolo III, J. R.; Bierman, M. J.; Strandwitz, N. C.; Kelzenberg, M. D.; Brunschwig, B. S.; Atwater, H. A.; Lewis, N. S. Photoanodic Behavior of Vapor-Liquid-Solid-Grown, Lightly Doped, Crystalline Si Microwire Arrays. Energy \& Environmental Science 2012, 5, 6867-6871.

(53) Yalamanchili, S.; Kempler, P. A.; Papadantonakis, K. M.; Atwater, H. A.; Lewis, N. S. Integration of Electrocatalysts with Silicon Microcone Arrays for Minimization of Optical and Overpotential Losses during Sunlight-Driven Hydrogen Evolution. Sustainable Energy \& Fuels 2019.

(54) Lewis, N. S.; Bocarsly, A. B.; Wrighton, M. S. Heterogeneous Electron Transfer at Designed Semiconductor/Liquid Interfaces. Rate of Reduction of SurfaceConfined Ferricenium Centers by Solution Reagents. The Journal of Physical Chemistry 1980, 84, 2033-2043.

(55) Bocarsly, A. B.; Walton, E. G.; Wrighton, M. S. Use of Chemically Derivatized nType Silicon Photoelectrodes in Aqueous Media. Photooxidation of Iodide, Hexacyanoiron(II), and Hexaammineruthenium(II) at Ferrocene-Derivatized Photoanodes. Journal of the American Chemical Society 1980, 102, 3390-3398.

(56) Maldonado, S.; Plass, K. E.; Knapp, D.; Lewis, N. S. Electrical Properties of Junctions between $\mathrm{Hg}$ and $\mathrm{Si}(111)$ Surfaces Functionalized with Short-Chain Alkyls. Journal of Physical Chemistry C 2007, 111, 17690-17699.

(57) Johansson, E.; Boettcher, S. W.; O’Leary, L. E.; Poletayev, A. D.; Maldonado, S.; Brunschwig, B. S.; Lewis, N. S. Control of the pH-Dependence of the Band Edges of Si(111) Surfaces Using Mixed Methyl/Allyl Monolayers. The Journal of Physical Chemistry C 2011, 115, 8594-8601.

(58) Sze, S. M.; Ng, K. K. Physics of Semiconductor Devices; 3rd ed.; John Wiley \& Sons, Inc.: Hoboken, NJ, USA, 2007.

(59) Nakato, K.; Takabayashi, S.; Imanishi, A.; Murakoshi, K.; Nakato, Y. Stabilization of n-Si Electrodes by Surface Alkylation and Metal Nano-Dot Coating for Use in Efficient Photoelectrochemical Solar Cells. Solar Energy Materials and Solar Cells 2004, 83, 323-330.

(60) Bruce, J. P. Surface Functionalization of Silicon Microwires for Use in Artificial Photosynthetic Devices, M.S. Thesis, University of Manitoba, 2014. 
(61) Wong, K. T.; Lewis, N. S. What a Difference a Bond Makes: The Structural, Chemical, and Physical Properties of Methyl-Terminated Si(111) Surfaces. Accounts of Chemical Research 2014, 47, 3037-3044.

(62) Deutsch, T.; Turner, J.; Leisch, J.; Wang, H.; Welch, A.; Lindeman, A.; O’Neill, K.; Pinkard, A.; Dameron, A.; Heske, C.; et al. Stable Photoelectrode Surfaces and Methods. US20140332374 A1, November 13, 2014.

(63) Nielander, A. C.; Bierman, M. J.; Petrone, N.; Strandwitz, N. C.; Ardo, S.; Yang, F.; Hone, J.; Lewis, N. S. Photoelectrochemical Behavior of n-Type Si(111) Electrodes Coated with a Single Layer of Graphene. Journal of the American Chemical Society 2013, 135, 17246-17249.

(64) Sikes, H. D.; Smalley, J. F.; Dudek, S. P.; Cook, A. R.; Newton, M. D.; Chidsey, C. E.; Feldberg, S. W. Rapid Electron Tunneling through Oligophenylenevinylene Bridges. Science 2001, 291, 1519-1523.

(65) Bookbinder, D. C.; Bruce, J. A.; Dominey, R. N.; Lewis, N. S.; Wrighton, M. S. Synthesis and Characterization of a Photosensitive Interface for Hydrogen Generation: Chemically Modified p-Type Semiconducting Silicon Photocathodes. Proceedings of the National Academy of Sciences 1980, 77, 6280-6284.

(66) Abruna, H. D.; Bard, A. J. Semiconductor Electrodes. 40. Photoassisted Hydrogen Evolution at Poly(Benzyl Viologen)-Coated p-Type Silicon Electrodes. Journal of the American Chemical Society 1981, 103, 6898-6901.

(67) Trotochaud, L.; Mills, T. J.; Boettcher, S. W. An Optocatalytic Model for Semiconductor-Catalyst Water-Splitting Photoelectrodes Based on In Situ Optical Measurements on Operational Catalysts. The Journal of Physical Chemistry Letters 2013, 4, 931-935.

(68) Liu, P.; Cao, Y.; Li, G.-R.; Gao, X.-P.; Ai, X.-P.; Yang, H.-X. A Solar Rechargeable Flow Battery Based on Photoregeneration of Two Soluble Redox Couples. ChemSusChem 2013, 6, 802-806.

(69) Yu, M.; McCulloch, W. D.; Beauchamp, D. R.; Huang, Z.; Ren, X.; Wu, Y. Aqueous Lithium-Iodine Solar Flow Battery for the Simultaneous Conversion and Storage of Solar Energy. Journal of the American Chemical Society 2015, 137, 8332-8335.

(70) McCulloch, W. D.; Yu, M.; Wu, Y. pH-Tuning a Solar Redox Flow Battery for Integrated Energy Conversion and Storage. ACS Energy Letters 2016, 1, 578-582.

(71) McKone, J. R.; DiSalvo, F. J.; Abruña, H. D. Solar Energy Conversion, Storage, and Release Using an Integrated Solar-Driven Redox Flow Battery. Journal of Materials Chemistry A 2017, 5, 5362-5372.

(72) Li, W.; Fu, H.-C.; Zhao, Y.; He, J.-H.; Jin, S. 14.1\% Efficient Monolithically Integrated Solar Flow Battery. Chem 2018, 4, 2644-2657.

(73) Liao, S.; Zong, X.; Seger, B.; Pedersen, T.; Yao, T.; Ding, C.; Shi, J.; Chen, J.; Li, C. Integrating a Dual-Silicon Photoelectrochemical Cell into a Redox Flow Battery for Unassisted Photocharging. Nature Communications 2016, 7, 11474. 